\title{
PENGARUH PENDIDIKAN KEWIRAUSAHAAN DAN EFIKASI DIRI TERHADAP INTENSI WIRAUSAHA MAHASISWA UNIVERSITAS TARUMANAGARA
}

\author{
Lita Indahsari dan Ida Puspitowati \\ Program Studi Manajemen Fakultas Ekonomi Universitas Tarumanagara, Jakarta \\ Email: litaindahsar@gmail.com
}

\begin{abstract}
The purpose of this research is to empirically examine the relationship between Entrepreneurship Education and Self-Efficacy towards Entrepreneurial Intention of Students Universitas Tarumanagara. The population of this research is 150 respondents of Students on Faculty of Economics and Business, Universitas Tarumanagara. Data are collected by using Google Form questionnaire then processed by using SmartPLS-SEM program. The method used in this research was non probability sampling with judgemental sampling tecnhnique. The results of this research are Entrepreneurship Education has a significant effect on Entreprenurial Intention. Self Efficacy has a significant effect on Entrepreneurial Intention.
\end{abstract}

Keywords: Entrepreneurship Education, Self-Efficacy and Entrepreneurial Intention

\begin{abstract}
Abstrak: Tujuan dari penelitian ini adalah untuk menguji secara empiris hubungan pendidikan kewirausahaan dan efikasi diri terhadap intensi wirausaha Mahasiswa Universitas Tarumanaga. Populasi dari penelitian ini sebesar 150 responden yang merupakan Mahasiswa/I Fakultas Ekonomi dan Bisnis Universitas Tarumangara. Teknik penggumpulan data dilakukan dengan penyebaran kuisioner melalui Google Form dan kemudian diolah menggunakan program SmartPLS-SEM. Metode pengambilan sampel yang digunakan dalam penelitian ini adalah non probability sampling dengan teknik judgemental sampling. Hasil dari penelitian ini menunjukkan bahwa pendidikan kewirausahaan berpengaruh signifikan terhadap intensi wirausaha. Efikasi diri berpengaruh signifikan terhadap intensi wirausaha.
\end{abstract}

Kata Kunci: Pendidikan Kewirausahaan, Efikasi Diri, dan Intensi Wirausaha

\section{LATAR BELAKANG}

Pengangguran merupakan salah satu permasalahan ekonomi yang masih dihadapi di Indonesia. Salah satu dampak akibat maraknya pengangguran yaitu kemiskinan. Pengangguran dan kemiskinan sangat berpengaruh pada perekonomian yang mengakibatkan pertumbuhan ekonomi dan juga tingkat kesejahteraan masyarakat menurun. Faktor maraknya pengangguran dan kemiskinan terjadi karena perbandingan antara jumlah penawaran kesempatan kerja tidak sebanding dengan jumlah lulusan atau penawaran tenaga kerja baru di segala level pendidikan (Saiman, 2009). Berdasarkan data dari Badan Pusat Statistik Indonesia pada tahun 2020 (BPS, 2020) menunjukkan jumlah pengangguran di Indonesia mencapai angka 6,88 juta jiwa. Menurut tingkat pendidikan, penggangguran didominasi oleh Sekolah Menengah Kejuruan (SMK) 8,49\%, disusul Sekolah Menengah Atas (SMA) sebesar 6,77\%, Diploma 6,76\%, Sarjana 5,73\%, Sekolah Menengah Pertama (SMP) 5,02\%, dan Sekolah Dasar ke bawah 2,64\%. Hal ini diperburuk dengan kondisi pandemi Covid-19 yang berlangsung sejak bulan Februari 2020, berdasarkan data Badan Pusat Statistik dimana tingkat pengangguran terbuka pada provinsi DKI Jakarta bulan Agustus sebesar 10,95\% atau setara dengan 572.780 jiwa. Bila dibandingkan 
dengan Agustus tahun lalu, pengangguran DKI Jakarta naik sebesar 4,41 \% atau bertambah 233.378 jiwa. Berdasarkan data tersebut, dapat dilihat bahwa jumlah persentase pengangguran tingkat sarjana pada tahun 2020 di Indonesia masih cukup besar dan jumlah pengangguran di Indonesia termasuk Jakarta mengalami kenaikan.

Para sarjana diharapkan mampu menjadi sumber daya manusia yang terampil dan berkualitas agar mampu bersaing. Namun pada kenyatannya para sarjana masih sulit bersaing untuk mendapatkan pekerjaan. Salah satu faktor utamanya yaitu dengan adanya kerja sama MEA (Masyarakat Ekonomi ASEAN) yang diberlakukan sejak Desember 2015 yang membentuk sistem perdagangan bebas / free trade antara negara-negara anggota ASEAN sehingga dapat dengan mudah tenaga kerja asing tinggal dan bekerja di Indonesia, selanjutnya menyebabkan persaingan untuk mendapatkan pekerjaan semakin ketat. Dengan adanya permasalahan pengangguran tersebut para sarjana diharapkan mampu menciptakan lapangan pekerjaan sendiri atau berwirausaha sehingga mampu berkontribusi dalam meningkatkan perekonomian Indonesia dan tidak memposisikan diri mereka sebagai karyawan. Menurut Kasmir (2011), wirausaha adalah orang yang berjiwa berani mengambil resiko untuk membuka usaha dalam berbagai kesempatan. Seorang yang melakukan kegiatan wirausaha disebut dengan wirausahawan atau entrepreneur. Seorang sarjana yang berkualitas sangat dibutuhkan dalam membangun suatu wirausaha agar mampu menciptakan lapangan pekerjaan dengan bekal pendidikan kewirausahaan yang mereka pelajari di Universitas. Pihak perguruan tinggi (universitas) bertanggung jawab dalam memberikan pendidikan termasuk pendidikan kewirausahaan serta memberikan motivasi sehingga menumbuhkan jiwa berwirausaha pada mahasiswa. Menumbuhkan jiwa kewirausahaan para mahasiswa di perguruan tinggi dipercaya merupakan solusi alternatif sebagai jalan keluar untuk mengurangi tingkat pengangguran, karena para sarjana diharapkan dapat menjadi wirausahawan muda terdidik yang mampu merintis usahanya sendiri menurut Suharti dan Sirine (2011).

Pendidikan kewirausahaan yang diberikan oleh Universitas tidak hanya memberikan ilmu pengetahuan, tetapi juga diharapkan dapat membentuk sikap dan pandangan mahasiswa agar berintensi menjadi. Hal ini dimungkinkan karena di Universitas para sarjana rata-rata sudah dibekali pendidikan Kewirausahaan. Pendidikan kewirausahaan merupakan salah satu mata kuliah yang harus diikuti oleh mahasiswa khususnya di Universitas Tarumanagara. Menurut penelitian Hidayati (2015), pengambilan keputusan pada intensi wirausaha ditentukan oleh dua faktor yaitu faktor internal maupun faktor eksternal. Hasil penelitian menunjukkan bahwa faktor internal seperti prestasi, motivasi, keyakinan diri (self-efficacy) dan sikap wirausaha ditemukan berpengaruh terhadap pengambilan keputusan menjadi wirausaha. Sementara itu, faktor eksternal seperti lingkungan keluarga, lingkungan sosial, dan pendidikan juga menunjukkan berpengaruh terhadap pengambilan keputusan untuk berwirausaha. Self-efficacy memiliki arti keyakinan (persepsi) individu mengenai kemampuan untuk membentuk suatu perilaku berwirausaha (Wijaya, 2008). Seorang wirausahawan harus memiliki keyakinan diri yang tinggi bahwa mereka mampu mengelola usahanya dengan baik. Keyakinan ini sangat dibutuhkan oleh mahasiswa dalam menumbuhkan intensi wirausaha.

\section{KAJIAN TEORI}

\section{Pendidikan Kewirausahaan}

Menurut Retno dan Trisnadi (2012) Pendidikan kewirausahaan adalah proses pembelajaran untuk mengubah pola pikir dan sikap mahasiswa terhadap pemilihan karir berwirausaha. Ediagbonya (2013) mengemukakan bahwa pendidikan kewirausahaan adalah jenis pendidikan yang diberikan kepada seseorang dengan tujuan tertentu untuk mengembangkan kegiatan wirausaha dan didukung secara penuh demi kelancaran dan keberhasilan suatu usaha. Chang dan Rieple (2013) menjelaskan bahwa pendidikan 
kewirausahaan bermaksud untuk mengembangkan pola pikir, keterampilan, kemampuan dan perilaku peserta didik untuk menciptakan wirausahawan di masa depan.

\section{Efikasi Diri}

Efikasi diri (Self-efficacy) merupakan keyakinan atau kepercayaan individu mengenai kemampuan dirinya dalam melakukan suatu tugas, mengorganisasi, menghasilkan sesuatu, mencapai suatu tujuan dan mengimplementasi tindakan untuk menampilkan kecakapan tertentu (Bandura, 1997). Ormrod (2008) berpendapat bahwa self-efficacy adalah keyakinan bahwa seseorang mampu menjalankan perilaku tertentu untuk mencapai tujuan tertentu. Cromie (2000) menjelaskan bahwa efikasi diri mempengaruhi kepercayaan seseorang akan tercapai atau tidaknya suatu tujuan yang sudah ditetapkan.

\section{Intensi Wirausaha}

Ajzen (1991) mengemukakan bahwa intensi diasumsikan sebagai faktor motivasi yang mempengaruhi perilaku dalam mengindikasi seberapa keras orang mau mencoba, seberapa banyak upaya yang mereka rencanakan untuk melakukan sesuatu. Gerba (2012) mengungkapkan bahwa intensi wirausaha sebagai kondisi dan dorongan dimana seseorang agar mengambil alih untuk berwirausaha ataupun mempunyai usaha sendiri bukan untuk dipekerjakan oleh orang lain. Intensi wirausaha berarti seseorang yang berkeinginan untuk memulai usaha sendiri. (Soumjaya \& Alexander, 2016)

\section{Kaitan antara Pendidikan Kewirausahaan dan Intensi Wirausaha}

Frank dkk (2005) menyatakan bahwa pendidikan kewirausahaan dipersiapkan untuk mengajak masyarakat terutama generasi muda, untuk menjadi bertanggung jawab, serta individu yang giat dalam menjadi seorang wirausaha atau seorang wirausaha yang berkontribusi dalam pembangunan ekonomi dan masyarakat yang berkelanjutan. Fayolle dan Gailly (2015) meyakini bahwa pendidikan yang berfokus pada kewirausahaan merupakan wahana bagi generasi muda dalam upaya mengembangkan intensi kewirausahaan. Hal ini diperkuat oleh teori Lestari dan Wijaya (2012) yang menyatakan bahwa pendidikan kewirausahaan dapat membentuk pola pikir, sikap, dan perilaku pada mahasiswa agar menjadi seorang wirausahawan sejati sehingga mengarahkan mereka untuk memilih berwirausaha sebagai pilihan karir. pendidikan kewirausahaan diberikan guna mengembangkan kegiatan yang menerapkan tentang kewirausahaan pada seseorang ataupun mahasiswa demi tercapainya keberhasilan suatu usaha.

H1 : Terdapat hubungan yang signifikan antara pendidikan kewirausahaan dan intensi wirausaha Mahasiswa/I Fakultas Ekonomi dan Bisnis Universitas Tarumanagara

\section{Kaitan antara Efikasi Diri dan Intensi Wirausaha}

Efikasi diri dalam berwirausaha mempunyai peran yang sangat meyakinkan terhadap dorongan berwirausaha (Zhao dkk, 2005). Mahasiswa yang memiliki efikasi diri tinggi cenderung menunjukkan minat intrinsik yang lebih tinggi dalam berkegiatan dan berperilaku mengenai hal-hal kewirausahaan. Menurut Shane, dkk. (2003) seorang wirausahawan yang memiliki self-efficacy yang tinggi kemungkinan akan mengerahkan lebih banyak upaya untuk jangka waktu yang lebih lama, bertahan melalui kemunduran, dan mengembangkan rencana dan strategi yang lebih baik untuk tugas tersebut. Semakin tinggi rasa percaya diri dan besarnya dorongan keyakinan mahasiswa maka semakin tinggi pula intensi berwirausahanya.

H2 : Terdapat hubungan yang signifikan antara efikasi diri dan intensi wirausaha Mahasiswa/I Fakultas Ekonomi dan Bisnis Universitas Tarumanagara.

Berdasarkan uraian kaitan antar variabel yang sudah dijelaskan di atas, maka model penelitian yang akan digunakan dalam penelitian ini adalah sebagai berikut : 


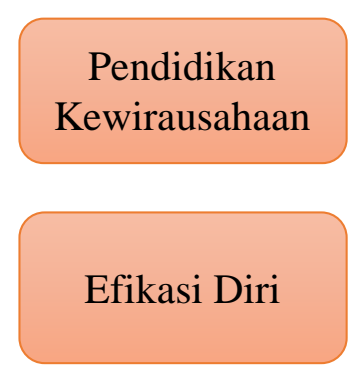

Pendidikan

Kewirausahaan

Efikasi Diri
H1

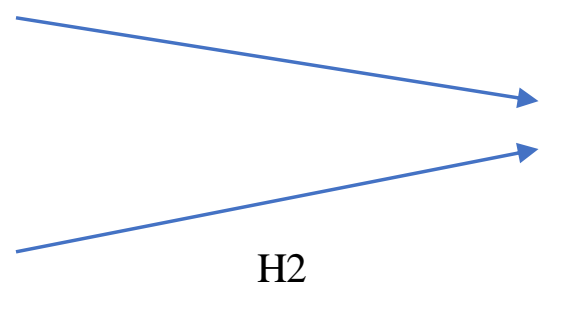

Gambar 1

Model Penelitian

\section{METODOLOGI}

Hasil penelitian diperoleh berdasarkan pembagian kuesioner melalui Google Form kepada Mahasiswa Universitas Tarumanagara. Populasi dalam penelitian ini yaitu 150 responden yang merupakan Mahasiswa/I Fakultas Ekonomi dan Bisnis Universitas Tarumanagara. Teknik pemilihan sampel dalam penelitian ini menggunakan metode Non Probability Sampling dengan teknik Judgment Sampling. Variabel operasional dalam penelitian ini terdiri dari Pendidikan Kewirausahaan dan Efikasi Diri sebagai variabel independen, dan Intensi Wirausaha sebagai varibel dependen. Pengujian statistik yang digunakan dalam penelitian ini menggunakan aplikasi SmartPLS Versi 3.3

Berdasarkan data yang diperoleh dari 150 responden, dapat dijabarkan melalui kriteria dan beberapa kategori yaitu semester dan jenis kelamin responden. Kriteria responden yang merupakan Mahasiswa/I Fakultas Ekonomi dan Bisnis Universitas Tarumanagara dan sudah memperlajari mata kuliah Dasar-Dasar Kewirausahaan menunjukkan bahwa seluruh responden menjawab "Ya" sebanyak $100 \%$. Metode pengujian pada penelitian ini menggunakan inner model (model struktural) dan Outer Model (model pengukuran). Inner model terdiri dari : Convergent Validity, Avearage Variance Extract, Composite Reliable dan Alpha Cronbach. Sedangkan Outer model terdiri dari : Coefficient of Determination (R2), Effect Size (F2), Predictive Relevance (Q2), dan Path Coefficients. Goodness of Fit (GoF), dan hasil uji hipotesis.

\section{Hasil Uji}

Hasil uji menjelaskan hasil dari PLS Algorithm, bootstrapping dan Blindfolding pada aplikasi SmartPLS. Menurut Hair, dkk. (2014), validitas dapat diukur dengan Convergent Validity dengan varian Average Variance Extracted (AVE) harus lebih besar dari 0,50 $(>0,50)$ dan nilai loading faktor yang diharapkan $>0,7$.

Tabel 1. Hasil Nilai Average Variance Extracted (AVE)

\begin{tabular}{|c|c|c|}
\hline Variabel & $\begin{array}{c}\text { Average Variance } \\
\text { Extracted }(\boldsymbol{A V E})\end{array}$ & Keterangan \\
\hline $\begin{array}{c}\text { Pendidikan Kewirausahaan } \\
(\mathrm{X} 1)\end{array}$ & 0,617 & Valid \\
\hline Efikasi Diri (X2) & 0,579 & Valid \\
\hline
\end{tabular}




\begin{tabular}{|c|c|c|}
\hline Intensi Wirausaha (Y) & 0,565 & Valid \\
\hline
\end{tabular}

Sumber : Hasil pengolahan data SmartPLS

Dalam penelitian ini, hasil pengujian Average Variance Extracted (AVE) dari variabel Pendidikan Kewirausahaan (X1) memiliki nilai 0,617>0,50 variabel Efikasi Diri (X2) memiliki nilai 0,579>0,50 dan pada variabel Intensi Wirausaha $(\mathrm{Y})$ memiliki nilai 0,565 > 0,50 sehingga dapat dinyatakan bahwa data penelitian ini valid.

Tabel 2. Hasil Nilai Loading Factors

\begin{tabular}{|c|c|c|}
\hline Kode & Pernyataan & Loading Factors \\
\hline PK1 & $\begin{array}{l}\text { Pendidikan kewirausahaan meningkatkan } \\
\text { pemahaman saya dalam merencanakan suatu } \\
\text { usaha }\end{array}$ & 0,876 \\
\hline PK2 & $\begin{array}{l}\text { Pendidikan kewirausahaan meningkatkan } \\
\text { kemampuan saya dalam melihat peluang usaha }\end{array}$ & 0,786 \\
\hline PK3 & $\begin{array}{l}\text { Pendidikan kewirausahaan meningkatkan } \\
\text { kemampuan saya dalam menghasilkan ide-ide } \\
\text { inovatif }\end{array}$ & 0,796 \\
\hline PK4 & $\begin{array}{l}\text { Pendidikan kewirausahaan meningkatkan } \\
\text { pemahaman saya mengenai sikap menjadi } \\
\text { seorang pengusaha }\end{array}$ & 0,730 \\
\hline PK5 & $\begin{array}{l}\text { Pendidikan kewirausahaan meningkatkan } \\
\text { keterampilan saya dalam menangani resiko dan } \\
\text { ketidakpastian }\end{array}$ & 0,731 \\
\hline ED1 & $\begin{array}{l}\text { Saya mengetahui cara untuk mengembangkan } \\
\text { suatu usaha }\end{array}$ & 0,823 \\
\hline ED2 & $\begin{array}{l}\text { Saya mengetahui secara detail kebutuhan yang } \\
\text { diperlukan dalam memulai suatu usaha }\end{array}$ & 0,728 \\
\hline ED3 & $\begin{array}{l}\text { Memulai suatu usaha dan membuat usaha tetap } \\
\text { berjalan akan mudah bagi saya }\end{array}$ & 0,747 \\
\hline ED4 & $\begin{array}{l}\text { Saya siap dalam membangun suatu usaha yang } \\
\text { layak }\end{array}$ & 0,742 \\
\hline IW1 & $\begin{array}{l}\text { Saya akan memilih karir sebagai seorang } \\
\text { pengusaha }\end{array}$ & 0,745 \\
\hline IW2 & $\begin{array}{l}\text { Sangat menarik bagi saya jika suatu hari nanti } \\
\text { saya dapat memulai bisnis saya sendiri }\end{array}$ & 0,807 \\
\hline IW3 & $\begin{array}{l}\text { Saya lebih suka menjadi seorang pengusaha } \\
\text { daripada menjadi karyawan }\end{array}$ & 0,758 \\
\hline IW4 & $\begin{array}{l}\text { Saya ingin memiliki kebebasan berekspresi } \\
\text { dalam membangun usaha saya sendiri }\end{array}$ & 0,723 \\
\hline
\end{tabular}




\begin{tabular}{|c|l|c|}
\hline IW5 & $\begin{array}{l}\text { Saya dapat menghasilkan banyak uang jika } \\
\text { saya menjadi seorang pengusaha }\end{array}$ & 0,732 \\
\hline IW6 & $\begin{array}{l}\text { Kisah pengusaha sukses menginspirasi saya } \\
\text { menjadi seorang pengusaha }\end{array}$ & 0,743 \\
\hline
\end{tabular}

Sumber : Hasil pengolahan data SmartPLS

Berdasarkan pada nilai AVE dan nilai Loading Factor yang telah dijabarkan diatas, setiap indikator mempunyai nilai Loading Factors yang lebih besar dari 0,7 (>0,7). Indikator yang mempunyai nilai terendah terdapat pada pernyataan kode IW4 yaitu mempunyai nilai sebesar 0,723 sedangkan, indikator yang mempunyai nilai tertinggi terdapat pada pernyataan kode PK1 yaitu mempunyai nilai sebesar 0,876 . Selain itu berdasarkan hasil pengujian Average Variance Extracted (AVE) Varibel Pendidikan Kewirausahaan (X1), Efikasi Diri (X2) dan Intensi Wirausaha (Y) menunjukkan nilai lebih besar dari 0,5 maka dapat disimpulkan bahwa nilai AVE dan nilai Loading Factor dianggap valid.

Tabel 3. Hasil Uji Reliabilitas

\begin{tabular}{|c|c|c|c|}
\hline Variabel & Alpha Cronbach & $\begin{array}{c}\text { Composite } \\
\text { Reliable }\end{array}$ & Keterangan \\
\hline Pendidikan Kewirausahaan & 0,843 & 0,889 & Reliabel \\
$(\mathrm{X} 1)$ & & & Reliabel \\
\hline Efikasi Diri (X2) & 0,756 & 0,846 & Reliabel \\
\hline Intensi Wirausaha (Y) & 0,846 & 0,886 & \\
\hline
\end{tabular}

Sumber : Hasil pengolahan data SmartPLS

Menurut Khumaedi (2012) Uji reliabilitas merupakan koefisien yang menunjukan sejauh mana suatu alat pengukur dapat dipercaya, artinya apabila suatu instrument digunakan berulangulang untuk mengukur suatu yang sama, maka hasilnya stabil atau konsisten. Uji reliabilitas dianggap reliable jika hasilnya lebih besar dari 0,70 menurut Hair, dkk, (2014). Berdasarkan hasil pengujian Alpha Cronbach dan Composite Reliable nilai pada setiap variabel pada penelitian ini menunjukkan hasil yang lebih besar dari $0,7(>0,7)$ maka dengan demikian, seluruh variabel dalam analisis reabilitas telah memenuhi syarat dan reliabel.

Setelah pengujian Outer Model, penelitian ini juga melakukan pengujian Inner Model. Menurut Sarstedt, Ringle dan Hair, (2017) pengujian koefisien determinasi mempunyai 3 kriteria, yaitu : $R$-Square 0,25 dikategorikan lemah, $R$-Square 0,50 dapat dikategorikan sedang dan jika nilai $R$ Square 0,75 maka dapat dikategorikan kuat.

Tabel 4. Hasil Uji Koefisien Determinasi

\begin{tabular}{|c|c|}
\hline Variabel & R-Square \\
\hline Intensi Wirausaha (Y) & 0,743 \\
\hline
\end{tabular}

Sumber : Hasil pengolahan data SmartPLS

Berdasarkan hasil pengujian koefisien determinasi, dapat diperoleh nilai $R$-Square dalam penelitian ini sebesar 0,743 dan dapat dikategorikan sedang. Artinya sebesar 74,3\% variabel 
intensi wirausaha di pengaruhi oleh variabel pendidikan kewirausahaan dan efikasi diri. Sedangkan sebesar 25,7\% variabel intensi wirausaha dipengaruhi oleh variabel lain yang tidak termasuk kedalam penelitian ini.

Tabel 5. Hasil Uji Effect Size

\begin{tabular}{|c|c|}
\hline Variabel & F-Square \\
\hline $\begin{array}{c}\text { Pendidikan Kewirausahaan (X1) terhadap Intensi } \\
\text { Wirausaha (Y) }\end{array}$ & 0,355 \\
\hline Efikasi Diri (X2) terhadap Intensi Wirausaha (Y) & 0,076 \\
\hline
\end{tabular}

Berdasarkan Hasil pengujian $f$-square ( $f 2$ ) pada SmartPLS versi 3.3, ditemukan bahwa nilai $\mathrm{F}^{2}$ pada variabel Pendidikan Kewirausahaan (X1) terhadap Intensi Wirausaha (Y) adalah sebesar 0,355 yang dapat diartikan pendidikan kewirausahaan memiliki efek yang besar terhadap intensi wirausaha. Dan pada variabel Efikasi Diri (X2) terhadap Intensi Wirausaha (Y) adalah sebesar 0,076, yang dapat diartikan bahwa efikasi diri memiliki efek yang kecil terhadap intensi wirausaha.

Tabel 6. Hasil Uji Relevansi Prediktif

\begin{tabular}{|c|c|}
\hline Variabel & Q-Square \\
\hline Intensi Wirausaha (Y) & 0,406 \\
\hline
\end{tabular}

Sumber : Hasil pengolahan data SmartPLS

Nilai Q-Square dapat diuji melalui teknik blindfolding pada aplikasi SmartPLS Versi 3.3 dan mengacu pada nilai Cross-validated Redundancy $\left(\mathrm{Q}^{2}\right)$. Hasil yang diperoleh dalam penelitian ini sebesar 0,406 yang dapat diartikan bahwa penelitian ini relevan untuk dipakai karna $\mathrm{Q}^{2}>0$.

Menurut Hair, dkk (2014) Jika nilai yang dihasilkan dari uji path coefficients mempunyai nilai di atas 0 hingga 1 dapat dikategorikan hubungan antar variabel tersebut mempunyai pengaruh yang positif. Menurut Ikhsania (2015) Untuk menentukan hipotesis diterima atau tidak ditolak maka pengujian menggunakan level signifikansi atau $p$-value $5 \%(0,5)$, memiliki nilai $t$ statistics $>1,96$ untuk hipotesis dua arah dan 1,64 untuk hipotesis satu arah.

Tabel 7. Hasil Uji Path Coefficient

\begin{tabular}{|c|c|c|c|}
\hline Variabel & $\begin{array}{c}\text { Original } \\
\text { Sample }\end{array}$ & T-Statistics & P-Values \\
\hline $\begin{array}{c}\text { Pendidikan Kewirausahaan (X1) } \\
\text { terhadap Intensi Wirausaha (Y) }\end{array}$ & 0,607 & 5,813 & 0,000 \\
\hline $\begin{array}{c}\text { Efikasi Diri (X2) terhadap Intensi } \\
\text { Wirausaha (Y) }\end{array}$ & 0,281 & 2,693 & 0,007 \\
\hline
\end{tabular}

Sumber : Hasil pengolahan data SmartPLS 
Nilai original sample yang dihasilkan pada hasil uji path coefficients pada pendidikan kewirausahaan (X1) terhadap intensi kewirausahaan (Y) adalah sebesar 0,607 > 0 maka dapat disimpulkan positif, dan nilai original sample yang dihasilkan pada hasil path coefficients pada efikasi diri (X2) terhadap intensi wirausaha (Y) adalah sebesar 0,281>0 maka dapat disimpulkan positif. Dari hasil uji Path Coefficient dapat diperoleh persamaan regresi ganda, yakni: IW = 0,607PK $+0,281 E D$. Dari persamaan tersebut dapat diartikan bahwa pengaruh variabel pendidikan kewirausahaan memiliki pengaruh yang positif terhadap variabel intensi wirausaha sebesar 0,607 dan variabel efikasi diri memiliki pengaruh positif terhadap variabel intensi wirausaha sebesar 0,281. Berikutnya, penelitian ini melakukan uji kecocokan (Goodness of Fit/GoF) dengan menghitung rata-rata AVE dengan $R$-Square, yang diperoleh hasil sebesar 0,6604 hasil ini termasuk dalam ketegori besar. Nilai GoF dibagi menjadi tiga bagian yaitu 0,1 (kecil), 0,25 (sedang) dan 0,36 (besar) menurut Tenenhaus (2005).

Langkah terakhir yang dilakukan dalam penelitian ini adalah uji hipotesis. Berdasarkan hasil pengujian hipotesis 1 (H1) pada variabel pendidikan kewirausahaan terhadap variabel intensi wirausaha pada Mahasiswa/I Fakultas Ekonomi dan Bisnis Universitas Tarumanagara dapat disimpulkan bahwa $\mathrm{H} 1$ diterima karena pendidikan kewirausahaan telah mememenuhi syarat ( $t$-statistics $>1,96$, $p$-values $<5 \%$ dan original samples $>0$ ) dengan hasil nilai $t$-statistics sebesar 5,560, nilai $p$-values sebesar 0,000 dan original samples sebesar 0,607. Berdasarkan hasil pengujian hipotesis $2(\mathrm{H} 2)$ variabel efikasi diri terhadap variabel intensi wirausaha, dapat disimpulkan bahwa hipotesis ini diterima karena nilai $t$-statistics, $p$-values dan original samples masing-masing sebesar 2,693 >1,96, 0,007<0,05, dan 0,281 >0 yang artinya semua nilai telah memenuhi ketentuan yang dapat disimpulkan semua hipotesis berhubungan positif dengan mempunyai pengaruh yang signifikan.

\section{DISKUSI}

1. Berdasarkan hasil pengujian variabel pendidikan kewirausahaan (X1) terhadap variabel intensi wirausaha (Y) pada Mahasiswa/I Fakultas Ekonomi dan Bisnis Universitas Tarumanagara dapat disimpulkan bahwa H1 tidak ditolak atau diterima karena pendidikan kewirausahaan telah mememenuhi syarat ( $t$-statistics $>1,96$ atau p-values $<$ $5 \%$ ). Pendidikan kewirausahaan terbukti berpengaruh positif dan signifikan terhadap intensi wirausaha. Hasil ini sejalan dengan hasil penelitian yang dilakukan oleh Patricia dan Kusumajanto (2018). Berdasarkan hasil penelitian yang telah dilakukan, diketahui bahwa pendidikan kewirausahaan berpengaruh positif dan signifikan terhadap intensi berwirausaha. Artinya semakin sering seseorang mendapatkan pendidikan kewirausahaan maka akan semakin besar pula niat berwirausaha. Menurut Gorman dkk. (1997) atribut wirausaha dapat mempengaruhi secara positif melalui program-program pendidikan serta pelatihan kewirausahaan yang dapat mampu meningkatkan kesadaran akan kegunaan kewirausahaan jika digunakan sebagai pilihan karir seseorang dan juga dapat mendorong menumbuhkan sikap intensi kewirausahaan seseorang. Hal ini membuktikan bahwa para mahasiswa yang sudah mempelajari pendidikan kewirausahaan dan sudah melakukan atau mempraktekan kegiatan kewirausahaan ratarata akan memiliki jiwa wirausaha pada dirinya. Dari beberapa penelitian yang telah dijelaskan sebelumnya dapat disimpulkan bahwa Pendidikan Kewirausahaan berpengaruh secara positif dan signifikan dalam meningkatkan intensi wirausaha. Hal ini dikarenakan pendidikan kewirausahaan melalui mata kuliah yang diberikan di Universitas serta program-program kewirausahaan seperti seminar, lomba dan implementasi suatu usaha dapat dibuktikan mampu menambahkan skill dalam berwirausaha dan dapat menumbuhkan intensi wirausaha pada mahasiswa. 
2. Berdasarkan hasil pengujian variabel efikasi diri (X2) terhadap variabel intensi wirausaha (Y), dapat disimpulkan bahwa $\mathrm{H} 2$ tidak ditolak atau diterima karena efikasi diri telah mememenuhi syarat dengan hasil nilai t-statistics sebesar 2,616 dan nilai p-values sebesar 0,009 ( $t$-statistics $>1,96$ atau $p$-values $<5 \%)$. Yang artinya efikasi diri terbukti positif dan signifikan mempengaruhi intensi wirausaha pada Mahasiswa/I Fakultas Ekonomi dan Bisnis Universitas Tarumanagara. Mahasiswa yang memiliki efikasi diri yang tinggi atau kemampuan dan keyakinan yang kuat dalam dirinya akan mampu melakukan sesuatu dengan sungguh-sungguh demi mencapai tujuan. Hal ini sejalan dengan penelitian Puspitanigtyas (2017) yang menyatakan bahwa tingginya efikasi diri mahasiswa akan mendorong keinginan untuk berwirausaha, terutama didorong oleh kepercayaan diri yang tinggi. Mahasiswa Indonesia memiliki kepercayaan diri terhadap kemampuan berwirausaha. Dari hasil penelitian yang telah dijelaskan sebelumnya dapat disimpulkan bahwa mahasiswa yang memiliki efikasi diri tinggi mampu mempengaruhi secara signifikan kesungguhan dan intensi mahasiswa dalam berwirausaha. Mahasiswa yang memiliki efikasi diri akan termotivasi untuk meningkatkan kualitas dan potensi yang dimiliki dalam memulai suatu wirausaha.

\section{PENUTUP}

Berdasarkan hasil penelitian dan juga pengujian data yang dilakukan dalam penelitian ini, menunjukkan bahwa pendidikan kewirausahaan dan efikasi diri berpengaruh positif dan signifikan terhadap intensi wirausaha Mahasiswa/I Fakultas Ekonomi dan Bisnis Universitas Tarumanagara.

Berdasarkan hasil penelitian yang telah dilakukan, saran yang dapat diberikan bagi penelitian selanjutnya yaitu diharapkan dapat mencakup variabel-variabel yang lebih luas yang secara signifikan dapat mempengaruhi intensi wirausaha. Salah satu contohnya variabel latar belakang keluarga, dikarenakan individu dengan latar belakang keluarga yang berwirausaha biasanya akan membentuk intensi wirausaha pada individu sejak dini. Dan juga saran bagi peneliti selanjutnya diharapkan dapat mengumpulkan data responden yang lebih banyak dan tidak hanya menetapkan populasi tertentu agar penelitian yang diteliti dapat digeneralisasikan dan dapat memperkuat hasil penelitian yang dilakukan oleh peneliti selanjutnya.

\section{DAFTAR PUSTAKA}

Ajzen, I. (1991). "The theory of planned behavior. Organizational Behavior and Human Decision Processes" 50(2), 179-211.

Badan Pusat Statistik. (2020) Februari 2020 Tingkat Pengangguran Terbuka (TPT) sebesar 4,99 persen (Retrieved From: www.bps.go.id / 9-11-2020)

Bandura, A. (1997). Self-Efficacy, the Exercise of Control. New York: W.H. Freeman and company.

Chang, J., \& Rieple, A. (2013). Assessing students. entrepreneurial skills development in live projects. J Small Bus Enterp Dev, 20(1), 225-241.

Cromie, S., (2000) "Assessing entrepreneurial inclinations: some approaches and empirical evidence." European Journal of Work and Organizational Psychology, 9(1), 7-30.

Ediagbonya, K. (2013) "The roles of entrepreneurship education in ensuring economic empowerment and development." Journal of Business Administration and Education, 4(1), $35-46$.

Fayolle, A., \& Gailly, B. (2015) "The impact of entrepreneurship education on entrepreneurial attitudes and intention: hysteresis and persistence." J Small Bus Manag, 53(1), 75-93. 
Frank, H., Korunka, C., Lueger, M., \& Mugler, J. (2005) "Entrepreneurial orientation and education in Austrian secondary schools." Journal of Small Business and Enterprise Development, 12(2), 259-273.

Gerba. D. T., (2012). "Impact of entrepreneurship education on entrepreneurial intentions of business and engineering students in Ethiopia." African Journal of Economic and Management Studies, 3(2), 258-277.

Gorman, G., Hanlon, D. \& King, W. (1997) "Some research perspectives on entrepreneurship education, enterprise education and education for smallbusiness management: a ten-year literature review." International Small Business Journal, 15(3), 56-77.

Hair Jr, J. F., Sarstedt, M., Hopkins, L., \& Kuppelwieser, V. G. (2014) "Partial Least Squares Structural Equation Modeling (PLS-SEM): an emerging tool in business research." European Business Review, 26(2), 106-121.

Hidayati, N. (2015). "Faktor-Faktor Yang Berpengaruh Terhadap Keputusan Berwirausaha dan Dampaknya Terhadap Kualitas Hidup (Studi Terhadap Wanita Wirausaha Kuliner di Jawa Tengah)" Jurnal pendidikan, 3(1), 7-13.

Kasmir. (2011). Kewirausahaan. Jakarta: PT. Raja Grafindo Persada.

M, Khumaedi. (2012) "Reliabilitas Instrumen Penelitian Pendidikan." Jurnal Pendidikan Teknik Mesin, 12(1), 25-30.

Ormrod, J., E. (2008). Psikologi Pendidikan (membantu siswa tumbuh dan berkembang jilid 2). Jakarta: Erlangga.

Patricia \& Kusumajanto (2018) "Effect of Entrepreneurship Education and Self Efficacy Towards The Intention of Entrepreneurship." Jurnal Pendidikan Bisnis dan Manajemen, 4(3), 128-133.

Retno, B. L., \& Trisnandi, W. (2012) "Pengaruh Pendidikan Kewirausahaan Terhadap Minat Berwirausaha Mahasiswa di STIE MDP, STMIK MDP, dan STIE MUSI." Jurnal Ilmiah STIE MDP, 1(2), 112-119.

Shane, S., Locke, E.A. and Collins, C.J. (2003), "Entrepreneurial motivation”. Human Resource Management Review, " 13 (2), 257-279.

Suharti, L., \& Sirine, H. (2011). "Faktor-faktor yang Mempengaruhi Terhadap Niat Kewirausahaan (Studi terhadap mahasiswa Universitas Kristen Satya Wacana, Salatiga)." Jurnal Manajemen Dan Kewirausahaan, 13(2), 124-125.

Soumyaja, D., \& Alexander, L. (2016) "A study on the influence of personality traits on entrepreneurial intention among working professionals in the Indian technical organizations." Pac Bus Rev Int, 9(5), 12-19.

Tenenhaus M, Vinzi VE, Chatelin YM, Lauro C (2005) "PLS path modeling." Comput Stat Data Anal, 48(1), 159-205.

Wijaya, T (2008) “Kajian Model Empiris Perilaku Berwirausaha UKM DIY dan Jawa tengah". Jurnal manajemen dan Kewirausahaan, 10(2), 93-104.

Zulfa, I., (2015) "Pengaruh Implementasi Internal Marketing Terhadap Kinerja Melalui Kepuasan Tenaga Kependidikan Di Fakultas Ekonomi Dan Bisnis Universitas Brawijaya Malang." Jurnal Ilmiah Administrasi Publik (JIAP), 1(2), 59-69.

Zahra, P. (2017) "Pengaruh Efikasi Diri dan Pengetahuan Manajemn Keuangan Bisnis Terhadap Intensi Berwirausaha." Jurnal Wira Ekonomi Mikroskil, 7(2), 141-150.

Zhao, H., Seibert, S. E., \& Hills, G. E. (2005) "The Mediating Role of SelfEfficacy ini the Development of Entrepreneurial Intentions." Journal of Applied Psychology, 90(6), 12651272. 